ConNotas. Revista de CRítica y teoría literarias / Vol. VI, Núm. 10 / 2008

\title{
Los que vinieron y los que se fueron: migrancias multipolares en la reciente narrativa venezolana ${ }^{1}$
}

\author{
CARlos Pacheco*
}

\author{
Está aquí lo que tú querías allá entre pastores, [...] \\ alrededor de tu aldea con muros medioevales \\ y vuelo de palomas en las tardes. [...] \\ Y tú estás aquí con el sudor de tu frente, \\ el solitario, el vestido de paño de hilo, \\ el erguido en medio de la comarca de las tempestades, \\ el que iba gritando hacia adentro, \\ buscándose las manos y la frente en la existencia, \\ buscando el sitio donde poder decir: \\ "Aquí yo vivo, aquí yo soy el hombre". \\ Vicente Gerbasi. Mi padre el inmigrante, Canto XIX
}

Resumen:

Desde la segunda posguerra hasta los años setenta, Venezuela atrajo un notable contingente migratorio. Desde entonces, el proceso se ha revertido por diversas razones políticas, económicas y sociales. En la primera parte de este trabajo se da cuenta de ese proceso y de la manera como ha impactado la literatura

\footnotetext{
${ }^{1}$ Sendas versiones preliminares de este trabajo fueron presentadas como ponencia en el XXVII Congreso de la Latin American Studies Asociation (LASA 2007) Montreal, Canadá (4 al 8 de septiembre de 2007), con el título de "Migrancias multipolares en la narrativa venezolana contemporánea: el caso de Miguel Gomes", y como conferencia magistral invitada en el XXI Coloquio Internacional de Literatura Mexicana e Hispanoamericana de la Universidad de Sonora. Hermosillo, México (7 al 9 de noviembre de 2007).

* Universidad Simón Bolívar.
} 
y en particular la narrativa venezolana. Con especial atención a las estrategias narrativas utilizadas para lograrlo, la segunda parte explora con mayor detalle la cuentística de Miguel Gomes, donde las migraciones y las muy diversas repercusiones de la condición migrante en Venezuela y Estados Unidos son representadas con alta eficiencia artística.

Palabras clave:

Migración, Migración venezolana, Migración y literatura, Literatura y política, Venezuela, Miguel Gomes, cuentos.

Durante los últimos años, la narrativa venezolana ha mostrado un desarrollo digno de atención que se manifiesta en nuevas colecciones editoriales, la creación y el fortalecimiento de varios certámenes literarios, el trabajo consistente de múltiples talleres, la aparición de blogs y revistas electrónicas sobre el tema y, probablemente lo más importante de todo, la proliferación de nuevos títulos, incluyendo varias antologías. ${ }^{2}$ Uno de los intereses temáticos que se detectan en este aún discreto pero indudable auge de la narrativa venezolana en el nuevo milenio es el que enfoca su atención en diversos aspectos, situaciones y personajes de las migraciones que han tenido lugar hacia y desde este país a la vez andino, caribeño y amazónico.

Esto último no es casual, puesto que, en el contexto hispanoamericano, Venezuela comparte con Argentina, y en menor medida con otros países, el haber sido por muchas décadas un poderoso magneto para migrantes de diversos orígenes, una nación constituida raigalmente por el arribo, la integración y la mezcla de individuos, familias y grupos poblacionales numerosos que por muy diversas razones económicas, sociales o políticas terminaron por transplantarse en busca de mejores condiciones de vida. Las profundas trans-

${ }^{2}$ Así lo han hecho notar desde hace ya algún tiempo varios críticos seguidores del acontecer de nuestra ficción como Antonio López Ortega, Carlos Pacheco, y Luis Barrera Linares. 
formaciones ocurridas en la sociedad venezolana en el último cuarto de siglo detuvieron e invirtieron esta corriente migratoria. Primero, los inmigrantes dejaron de venir. Desde los primeros ochenta muchos venezolanos comenzaron a marcharse.

"País de migrantes", se ha dicho; y la frase es perfectamente correcta, aunque en sentidos radicalmente distintos, más bien opuestos, si se contrasta el contexto histórico de mediados del siglo XX con el de comienzos del XXI. En el primero, especialmente entre la segunda postguerra y los años setenta, Venezuela atrajo amplios contingentes poblacionales de numerosos países europeos (en especial de España, Italia y Portugal) y no menos numerosos grupos provenientes de otras naciones hispanoamericanas y caribeñas, en especial de Colombia; así como de los países del Cono Sur en los años setenta, durante la sincrónica hegemonía de las dictaduras militares en Uruguay, Argentina y Chile.

En 1956 uno de cada cuatro adultos aptos para el trabajo era inmigrante reciente (Berglund). No es poco decir. A las oportunidades económicas que comenzaron a abrirse con la bonanza petrolera creciente desde los tiempos de Juan Vicente Gómez, a las bondades del clima y la permeabilidad social de los venezolanos, se unió más adelante la dinámica del proyecto modernizador que comenzó con el auge de la construcción de obras públicas durante la dictadura de Marcos Pérez Jiménez (1948-1958) y se amplió en el período democrático posterior a su derrocamiento con "la pacificación", que dio fin a la violencia política guerrillera en los primeros setenta y con el proyecto de expansión económica y política protagonizado, en la segunda mitad de esa década, por Carlos Andrés Pérez.

Fundada esencialmente en la renta petrolera, esa bonanza económica propició empleos con buenos salarios, atractivas oportunidades de educación y desarrollo empresarial y cultural; una estabilidad monetaria excepcional en Latinoamérica, una relativa paz pública en democracia desde 1958 y una incomparable movilidad social. Es más, desde finales de la década de los treinta el estado venezolano comenzó a implementar políticas de estímulo a la migración europea, principalmente con el fin de promover el desarrollo agrícola. Para muchos individuos desde entonces (y a menudo 
para sus familias, que venían a la zaga una vez estos ya asentados), durante ese largo período, en el cual sus respectivos países debieron afrontar muy duras condiciones de pobreza, escasez y falta de empleo, no hubo mejor lugar para desplazarse y establecerse. ${ }^{3}$

En lo étnico, lo cultural, lo socioeconómico y lo material, el país actual acusa de manera definida y evidente el influjo de esas migraciones, así como también, naturalmente, el de las más tempranas oleadas y la consiguiente mixtura de elementos culturales indígenas, europeos y africanos. Así que hasta el último cuarto del siglo XX puede considerarse a Venezuela un país de inmigrantes. Antes de los años 80 y por las razones antedichas, sólo merecen registrarse la salida de algunos exilados políticos de Juan Vicente Gómez (19081935) o de Marcos Pérez Jiménez, los viajes de estudiantes a partir de mediados de los años setenta para realizar estudios universitarios en el exterior con financiamiento público y, sobre todo, las giras de compras y turismo que hicieron no pocos venezolanos por esas mismas fechas, valiéndose de la fortaleza que por aquel entonces tenían nuestros bolívares. En todos estos casos, se trataba como es obvio de ausencias temporales y relativamente breves.

A partir de los tempranos años ochenta, el contexto económico, social y político comenzó a cambiar y con ello terminó por revertirse del todo el proceso migratorio. Primero, de manera no tan visible, a partir del tristemente recordado "viernes negro" (18 de febrero de 1983), cuando se interrumpió la notable estabilidad monetaria que por décadas había mantenido el precio del dólar a Bs. 4.30. Aquella

${ }^{3}$ En lo que respecta en particular a la inmigración portuguesa, el reciente y documentado libro de Antonio de Abreu Xavier, titulado Con Portugal en la maleta. Historias de vida de los portugueses en Venequela. Siglo XX, ofrece puntuales detalles. Documenta en efecto las carencias y penurias vividas por portugueses continentales e insulares, en especial durante el prolongado régimen nacionalista y autoritario de António de Oliveira Salazar (1932-1968). Refiere también los incentivos gubernamentales y las ventajas económicas y sociales que, en contraste, encontraban en la pujante Venezuela del medio siglo, que había encontrado en la renta petrolera el combustible necesario para lanzarse, de manera aún ingenua pero decidida, en pos de una acelerada modernización. 
fecha dio visibilidad al inicio de un proceso indetenible de gradual deterioro de la economía que tiene su vértice en la emblemática quiebra de numerosas instituciones bancarias, a pesar de los auxilios financieros oficiales, en 1994 y 1995.

Sincrónicamente con este deterioro económico y también de manera gradual, la alternancia en el poder de socialdemócratas y democristianos se va convirtiendo cada vez más en mera fachada democrática bajo la que prosperan el clientelismo, la corrupción y las mafias políticas, económicas y judiciales, mientras se dispara la inflación, aumenta la inseguridad y los logros de las décadas anteriores en salud, educación, obras de infraestructura y servicios públicos se van desmoronando. En ese contexto deficitario de fines de siglo se producen el episodio de insurrección popular conocido como "el Caracazo" (27 de febrero de 1990) y los dos intentos fallidos de golpe de estado del 4 de febrero y el 27 de noviembre de 1992.

Desde 1999, el Teniente Coronel Hugo Chávez, quien lideró directamente el primero de los golpes de estado de 1992, asume la presidencia de la república. Desde esa posición ha venido conduciendo el proceso autodenominado "revolución bolivariana", favorecido de manera muy importante por los recursos procedentes del nuevo boom petrolero derivado del aumento considerable de los precios del petróleo, que en nueve años pasó aproximadamente de 10 a 100 US \$ por barril. Durante este período, muchos venezolanos han encontrado nuevas y más poderosas razones para migrar, motivados por la polarización y la violencia política, la incertidumbre económica y la inseguridad jurídica, dominantes en un régimen que aprecian como autoritario y militarista, que ha desmontado la institucionalidad democrática con su proverbial contrapeso de poderes públicos. Estos nuevos y cada vez más numerosos migrantes son ahuyentados en particular por la inseguridad de los espacios públicos que amenaza ya gravemente la vida y los bienes de todo ciudadano, por la falta de condiciones económicas para la inversión y de empleo en instituciones públicas para los disidentes y por la oficialización del bolivarianismo o "socialismo del siglo XXI" como exclusiva ideología del Estado y las intenciones de Chávez de per- 
petuarse en el poder por tiempo indefinido, a pesar de su fracaso en el referéndum que ya le cerró legalmente ese camino el 2 de diciembre de 2007.

\section{Pero vayamos a la literatura}

Este complejo panorama político, con consecuencias económicas y sociales importantes que afectan la vida económica y social de cada uno de los venezolanos ha disparado un éxodo sin precedentes, principalmente hacia España y los Estados Unidos, que la ficción literaria no ha tardado en representar.

Muy bien sintetizado resulta, por ejemplo en un fragmento del e-mail que escribe a su hermana el protagonista de la novela $\mathrm{La}$ última vez (2006), de Héctor Bujanda, ganadora del Premio de Novela “Adriano González León” 2006:

Hola Katty: [...] Me alegra que ya estés adaptándote a tu nueva vida en Barcelona. Y que la ciudad sea tan amable como cuentas. [...]Creo que lo mejor que pudiste hacer fue irte a estudiar para afuera. [...] Después de vivir en Caracas, eso debe ser la Isla de la Fantasía, Katty. [...] Aquí se está yendo todo el mundo para el carajo. Es impresionante la estampida. Daniel Marín se fue para Miami y Esteban se va con la novia para Nueva York. El vecino está vendiendo todo para irse a Costa Rica a abrir una compañía de exportación. A veces me da un poco de temor quedarme aquí paralizado, teniendo a lo mejor posibilidad de estudiar en España, quizá en Madrid. Hacer la pasantía de El País, qué sé yo. [...] Ya veré, ya echaré los dados yo también. (Bujanda 29-30)

En el marco de una intriga policial vivida por una familia cuyo padre desaparece súbita y misteriosamente, esta novela muy bien construida muestra maravillosamente el deterioro institucional, la pérdida de calidad de vida y la polarización política característicos de la situación venezolana más reciente. Aunque no se dedica en 
particular a representar ese exilio forzoso de numerosos venezolanos de todas las clases sociales hacia países más desarrollados o al menos más seguros, al igual que muchas otras obras narrativas de los años recientes, registra el fenómeno con énfasis y sin margen de duda. Otros índices bastante elocuentes de esta tendencia en la vida real son el comportamiento del mercado inmobiliario, el incremento de las solicitudes de visa en los consulados y de autenticación de estudios por parte de estudiantes universitarios miembros de familias migrantes o (y esto no es una broma) el número de visitas electrónicas a la página <http://www.mequieroir.com $>4$

\section{La ficcionalización de las migraciones venezolanas}

En el libro colectivo Las migraciones a Venezuela en el siglo XX, Oscar Rodríguez Ortiz (2005) ofrece una valiosa panorámica de cómo son representados los inmigrantes en nuestra literatura contempo-

${ }^{4}$ El fenómeno llama la atención pública de tanto en tanto, como puede constarse en el reportaje reciente de Marielba Núñez en el diario ElNacional (Caracas, 27-01-08 p. A1, S1, S2 y S3) titulado "Se fuga la inteligencia", donde se destaca que 2.000 médicos (la mitad de todos los graduados en el período en Venezuela) se han ido a trabajar en el exterior en los últimos dos años, que 1.500 investigadores despedidos de Intevep (la filial de Petróleos de Venezuela dedicada a la investigación en tecnología petrolera de punta) durante el paro cívico del 2002 están trabajando en los mejores centros de desarrollo tecnológico en 32 diferentes naciones y que el portal <www.mequieroir.com> batió en 2007 su record de visitas, pasando de 20.000 a 60.000 consultas diarias. Muchos de los migrantes venezolanos son profesionales y no pocos cuentan con formación de postgrado que a menudo fue financiada por la Fundación Gran Mariscal de Ayacucho o las universidades públicas venezolanas. Según el reportaje, "Para 2001, datos de la National Science Foundation de Estados Unidos señalaban que 8.800 venezolanos trabajaban en ese país en actividades relacionadas con la ciencia y la tecnología en más de 7.000 en empresas o industrias, 2.000 con grado de magíster y 800 con doctorado. La mayoría de ellos había obtenido la nacionalidad estadounidense y 3 de cada 10 tenía visa de residente. La cifra es muy superior a las 5.222 personas que en 2007 estaban registradas en el Programa de Promoción del Investigador del Ministerio de Ciencia y Tecnología.“ (p. S2). Versión digital: <http://impresodigital.el-nacional.com/ediciones/2008/01/27/ default.asp?cfg=3512BLLH3097\&iu=6713> 
ránea, en especial por escritores venidos ellos mismos de otras partes del mundo o descendientes de inmigrantes. Primacía y relieve especial merece con razón en este registro el conocido poema extenso Mi padre el inmigrante (1945), de Vicente Gerbasi, obra entre las más logradas de uno de nuestros poetas mayores, donde la evocación y celebración del padre muerto y de la memoria infantil se convierte en inspirada relación lírica de las dificultades y deslumbramientos de un inmigrante del sur de Italia y su fecundidad en tierras venezolanas:

De todo tu andar de antiguo caminante, de todo tu sufrir en desamparo, de soportar el peso del hacha o del saco, $[\ldots]$ sólo te quedó una casa $[\ldots .$.

Aquella casa fue mi casa [...]

y allí estabas callado, con tus libros, junto a mi madre y a mis pequeños hermanos.

Allí estaban tus noches, todavía con las estrellas de otro mundo, y allí tu amorosa soledad, tu vida, tus recuerdos, $\mathrm{Y}$ allí estaba yo como una angustia para ti, y tu trabajo y el sudor de tu frente [...] y las lluvias nocturnas que nos lanzaban a un oscuro amanecer. ¡Estábamos tan cerca de los árboles, del río y la montaña!... Yo, con mi alegría donde cantaba el cristofué, tú, con tu vida dura, con golpes y nostalgias, de pie ante los días de mi infancia. $(\text { Canto XXIV })^{5}$

${ }^{5}$ No deja de resultar conmovedora la nota que el poeta coloca ante el primer canto del poema: "Mi padre, Juan Bautista Gerbasi, cuya vida es el motivo de este poema, nació en una aldea viñatera de Italia, a orillas del mar Tirreno, y murió en Canoabo, pequeño pueblo venezolano escondido en una agreste comarca del Estado Carabobo." Para una clarificadora lectura crítica y contextualización estética y biográfica de este poema, véase: "La refiguración del viaje: Mi padre el inmigrante de Vicente Gerbasi (1913-1992), de Victoria de Stefano. 
Como obras dignas de especial atención por su calidad literaria, destaca Rodríguez Ortiz la obra de teatro Rómpase en caso de incendio (1975), de Isaac Chocrón y las novelas Adiós hogar (1971), de Salvador Prasel y Cláper (1987), de Alicia Freilich, en las que se tejen historias relacionadas con la diáspora judía y su inserción en la sociedad venezolana.

Una investigación reciente de la manifestación literaria del fenómeno, emprendida por Gregory Zambrano en la Universidad de los Andes, ofrece como uno de sus primeros frutos un análisis de dos novelas que corresponden a la experiencia migratoria en los dos sentidos, hacia y desde Venezuela. Zarandona (1999), de Josu Landa, en primer lugar, cuenta la historia de un campesino así apellidado, convertido en mecánico industrial en los campos petroleros del Oriente del país y su muy numerosa familia, como imagen de la migración vasca a Venezuela en los años 50. Mientras tanto, Una tarde con campanas (2004) de Juan Carlos Méndez Guédez, centra su atención en los conflictos y fricciones, a menudo lingüísticos, vividos por los numerosos venezolanos, muchos de ellos descendientes directos de españoles, transplantados a España en las últimas dos décadas y convertidos en sudacas, como por arte de magia, por el solo hecho de aterrizar en el aeropuerto de Barajas.

Luz Marina Rivas (Literatura de la otredad y Las mujeres), por su parte, reporta la representación ficcional de los inmigrantes y su mundo en la cuentística de varias autoras de los años cincuenta, enfatizando el mundo de prejuicios mutuos que dificulta la integración social y lingüística. Se refiere en especial a los cuentos de Juana de Ávila ("El portugués" y "La loca”) y de Mireya Guevara ("La siembra humana", "Luis y la casa de Jelle" y "Las sirenas"). Rivas (Las mujeres y "El país") se refiere también a dos novelas mucho más recientes que serían parte de este corpus. La primera es Amargo y dulzón (2002), de Michaelle Ascensio, en la que una haitiana cuenta su llegada a Caracas siendo muy niña y su regreso a Haití, donde encuentra numerosos personajes migrantes y conflictos interculturales. ${ }^{6}$ La segunda es Te pienso en el puerto (2006) de Elisa Arráiz 
Lucca, donde se ficcionaliza la inmigración corsa a Venezuela a través principalmente de los puertos del oriente del país.

Las migraciones de los venezolanos han sido también internas. El desarrollo de la industria petrolera a partir de los años veinte y la atractiva dinámica de las ciudades, especialmente de Caracas, produjo movilizaciones importantes que en ocasiones provocaron el surgimiento de nuevas poblaciones como es el caso de El Tigre, en el estado Anzoátegui, cuyos orígenes tumultuosos y acelerado desarrollo aluvional han sido representados en las novelas Oficina $N^{o}$ 1 (1961), de Miguel Otero Silva y Memorias de una antigua primavera (1989), de Milagros Mata Gil. En relación con estas migraciones internas, parece interesante destacar cómo Aura Marina Boadas (2006) lee la narrativa de Renato Rodríguez como un discurso de la extranjeridad del isleño margariteño no sólo en el extranjero, sino en la porción continental de su propio país.

Como puede apreciarse, se trata de un corpus extenso y en desarrollo que merece una dedicación mucho mayor de la que nos es posible dedicar en este trabajo. No puede concluirse este sintético recorrido sin embargo sin referencia a una faceta que -hasta donde conozco- está aún por estudiarse. Se trata de la representación ficcional de la migración estudiantil que tuvo lugar a partir de 1975, gracias al programa de becas Gran Mariscal de Ayacucho. Varios miles de venezolanos viajaron para realizar sus estudios de pregrado y postgrado, especialmente a Europa y Norteamérica. Por las difíciles circunstancias que ha venido enfrentando Venezuela en los tiempos recientes, no pocos de estos estudiantes han preferido quedarse en el exterior al concluir sus estudios o han decidido migrar luego de enfrentar frustraciones laborales, económicas y ciudadanas al volver a la patria con su diploma bajo el brazo. Tanto Antonio López Ortega como José Luis Palacios se han interesado en ficcionalizar este fenómeno en varios de sus cuentos.

universitaria, ha estudiado como científica social las migraciones y el exilio en el Caribe (Ascencio). 


\section{La condición migrante en la obra de Miguel Gomes}

He elegido desarrollar el caso de Miguel Gomes (Caracas, 1964), porque en su narrativa la condición migrante está presente en toda la vastedad de sus manifestaciones. Como expresan numerosos trabajos de reflexión sobre este fenómeno (Todorov, Said, Cornejo Polar, Chambers, Stavans, García Canclini, Aínsa, entre otros) el transplante de individuos, familias, grupos de su lugar de origen a otras latitudes impacta la vida de los migrantes y sus nuevos contextos de residencia con una serie de perdurables consecuencias de orden psíquico, social, económico y cultural que han sido descritas, racionalizadas y conceptualizadas por los respectivos especialistas (como los esposos Grinberg, por ejemplo, desde la perspectiva del psicoanálisis), pero que el narrador de ficción registra y expone de manera mucho más vívida, más impactante, a menudo porque ha sido sujeto él mismo de esa experiencia de migrante.

Ese es precisamente el caso de Gomes. Su padre nació en una región apartada y pobre del noreste de Portugal llamada significativamente Trás-os-Montes y fue enviado a Madeira en los años cincuenta a prestar allí el servicio militar. Se casa con una madeirense y ante el peligro de ser enviado por el régimen dictatorial de Antonio de Oliveira Salazar a combatir en las guerras coloniales de Angola y Mozambique, se embarca para Venezuela. Miguel y otros hermanos nacieron ya en Caracas y allí se quedaron hasta terminar su educación universitaria al volver sus padres a Portugal en los tempranos ochenta. Después de concluir su doctorado como becario de Fundayacucho en la State University of New York (SUNY) en Stony Brook, Miguel se quedó a trabajar como profesor de la Universidad de Connecticut.

Muchos personajes e historias de su mundo ficcional pueden vincularse con esos tres elementos de su experiencia: el pasado pobre y tradicional de la familia lusitana; la infancia y adolescencia transcurridas en la vertiginosa Caracas de los 70 y 80 y, sobre todo, la posterior inserción en el medio universitario estadounidense. No se trata en absoluto de un calco de la realidad vivida por él o su familia con pretensión autobiográfica alguna, sino de contextos de cuyo 
conocimiento se vale productivamente para la invención ficcionalmente exitosa. A partir de esos elementos referenciales, su ficción se va expandiendo para incorporar vivencias semejantes a través de personajes también trashumantes, variantes sobre los mismos temas, sin dejar de reiterar en la mayoría de sus cuentos estos tres núcleos geoculturales del intercambio migratorio: el trasfondo lusitano (y también hispano), la experiencia juvenil venezolana y el presente laboral estadounidense.

De esa manera, sus cuentos despliegan una extensa gama de aspectos de la migrancia: las motivaciones políticas, económicas y personales de la partida, que puede ser elegida o forzada; el sentimiento de pérdida de todo lo dejado atrás y la consiguiente saudade o nostalgia del lar nativo, de su familia, su ritmo, su lengua y sus costumbres; la confusión ante lo nuevo y diferente, en especial el idioma del lugar de llegada; los esfuerzos por establecerse y adaptarse; el sufrimiento ante los prejuicios que lo segregan o disminuyen; el deseo y el proyecto de un posible regreso; la actitud (a veces no menos despreciativa) de las primeras y segundas generaciones ante los padres y abuelos migrantes y su cultura de origen; la relación con los "nativos" y con otros migrantes; la extrañeza de ser parte de la cultura propia del nuevo hábitat sin haber dejado de serlo de la (o las) cultura(s) de origen.

En muchos de los relatos gomesianos, sin embargo, en especial en los más recientes, los personajes están ya adaptados al nuevo medio o son miembros de una segunda o tercera generación, que nació y creció ya en él. De manera que las condiciones que para sus padres, o para esos mismos personajes tiempo atrás pudieron ser las penurias del desplazamiento y las dificultades de la adaptación, han venido a ser ahora más bien aportes, ventajas, elementos positivos; como el manejo fluido de varios idiomas, una experiencia más cosmopolita, unas visiones menos provincianas, mejor informadas y más tolerantes que las de los nativos; incluso las de los nativos de países industrializados como los Estados Unidos, que es el escenario predominante en las narraciones más recientes. Y como muchos de los protagonistas son intelectuales, en el sentido amplio de la palabra, el transplante viene a ser una enriquecedora condi- 
ción para sus prácticas como escritores, profesores, traductores, etc., la condición de haber superado las limitaciones de un nacionalismo estrecho, que puede llegar a ser agobiante y castrador, para aspirar a tener el mundo (o la literatura) como patria.

En las palabras iniciales de una esclarecedora conferencia pronunciada en la Escuela de Letras de la Universidad Central de Venezuela en octubre de 2007 y aún inédita, Fernando Aínsa cita a Flaubert declarando: "No soy más francés que chino y apenas entiendo lo que significa la patria", a Joyce exclamando: "iQue mi patria muera en mí!” y a Gombrowitcz afirmando: "Cuando escribo, no soy ni chino ni polaco", para luego elaborar sabiamente de esta manera:

Detrás de estas boutades y estas provocaciones, podía adivinarse el anhelo de fundar un espacio nuevo e independiente, lejos del solar nativo, con que se caracteriza buena parte de la literatura contemporánea. En esos territorios exteriores, donde se han refugiado quienes han hecho realmente sus maletas, se consagran el desarraigo, el exilio voluntario o forzoso, esa condición nomádica del artista contemporáneo que marca la narrativa del siglo XX, tendencia que no hace sino agudizarse en este nuevo milenio y que tiene sus particulares características en América Latina donde la literatura "transfronteriza" multiplica escenarios y puntos de vista desasida de toda noción estrecha de patria. Estas "figuras de afuera" -como las llama Kenneth White, para ampliar la idea política del exilio y la reductora imagen botánica del enraizamiento y el desarraigo- se inscriben en la condición que George Steiner llama la extraterritorialidad y la pluralidad lingüística que la acompaña, "carencia de hogar" que caracteriza la obra de grandes escritores como Nabokov, Borges y Beckett.

Pareciera además que el extrañamiento, el viaje, la superación de las fronteras no sólo o siempre es una pérdida. Puede ser también una ganancia. Páginas después, Aínsa expresa "Resulta así que un espacio nacional construido fuera de fronteras es no sólo posi- 
ble, sino que hasta parece recomendable." Y el habitar este espacio literario exterior, el asumirse en la propia obra intelectual como una "figura de afuera" no tiene por qué significar una desvinculación con el espacio literario de origen que continúa existiendo. De hecho, desde la perspectiva de las nociones de desterritorialización, globalización y difuminación de fronteras de todo orden, hoy día hoy día tan populares, en las cuales se relativiza al extremo la entidad y relevancia de los estados nacionales y, por consiguiente, los sentimientos de pertenencia y arraigo en ellos de los sujetos migrantes, uno hasta podría preguntarse si Gomes, nacido y educado en Caracas, pero descendiente de migrantes portugueses y establecido en los Estados Unidos desde hace casi 20 años, debería ser leído como parte de un constructo crítico-literario denominado "literatura venezolana”. Al ser interrogado al respecto, el narrador, ensayista y crítico responde positivamente sin ninguna vacilación. Aunque viva en los Estados Unidos y escriba sobre ese contexto de existencia, reconoce a la literatura venezolana no sólo como su punto de origen, sino también como una referencia cultural y artística importante, su principal ámbito de lectoría y su horizonte de desarrollo como escritor. De hecho sigue publicando principalmente en Venezuela y siguiendo el pulso de la literatura y la vida cultural de su país natal.

Así que la cuentística de Gomes exhibe como uno de sus rasgos distintivos más notables el estar en su mayor parte vinculada, de una manera diagonal y muy libre, pero constante y productiva, a la experiencia de la migración con la que ha estado en contacto directamente y a través de familiares, amigos y colegas. Sin la menor intención memorialista, documental o testimonial, lo heredado y lo vivido, lo experienciado y lo aprendido en este viaje geográfico y cultural, nutren esa obra de ficción con un valor sustantivo de verosimilitud y -si aún en tiempos tan posmodernos se permite tal concepto- de autenticidad. De hecho, me atrevería a decir que el valor de los relatos se incrementa en proporción directa a la fortaleza de ese vínculo. Y viceversa, en algunos de los cuentos con personajes y tramas más bien alejados de esa vivencia propia (como en el caso de "La montaña rusa", una suerte de homenaje a Quiroga 
protagonizado por migrantes venezolanos en Miami), esos valores decrecen, aunque no dejen de ser apreciables allí otras virtudes narrativas.

\section{La migrancia en cinco volúmenes}

El primero de sus libros, Visión memorable (1987), está compuesto por 48 textos muy breves, ejercicios preparatorios más bien, casi completamente despojados de ubicación geocultural explícita, que, sin mencionar su carácter de hijo de inmigrantes, nos hablan de un joven tímido y lector, acosado por la agresividad del medio humano y material que lo rodea en una ciudad aún no claramente identificada.

El segundo volumen, La cueva de Altamira (1992), consta de diez cuentos ya propiamente tales, con mayor dominio del instrumento narrativo, aunque aún en busca de ese "universo" propio. Centrado ahora sí nítidamente en Caracas, el narrador continúa percibiendo su entorno urbano como agresivo, asfixiante, pleno de acechanzas, un poco a la manera de algunos cuentos de Adriano González León y de su novela País portátil (1968). El tema de la inmigración está presente a cada paso y prácticamente en cada uno de los relatos, en los cuales encontramos múltiples acercamientos originales, en la mirada y la factura, a diversas historias de portugueses (en especial madeirenses), gallegos, vascos, catalanes, italianos. Aunque mucho menos contundente, se detecta también la presencia de colombianos y otros posibles hispanoamericanos "indocumentados". De un cuento a otro y amparados por la centenaria frase "hacer el traslado a Indias", de tan tradicional resonancia en la península Ibérica, van apareciendo los dramas de los inmigrantes que han dejado atrás a sus mujeres o que establecen vínculo con las llamadas "criollas", su desconcierto en el momento del arribo, su soledad y su espera del correo cuando se han decidido quedarse, tras el regreso de la familia al país de origen; su habla mezclada o su olvido de la lengua de sus padres, su crisis de identidad por desarraigo. 
"La cueva de Altamira", es el cuento epónimo del libro y será reiterado, en versión corregida, en el volumen posterior De fantasmas y destierros. Aparte La reiteración es acertada porque este cuento inaugura una línea central en la narrativa gomesiana; ésa en la que la vida y aventuras de los antepasados migrantes tratan de ser narradas (y así comprendidas) por un descendiente, quien a menudo es migrante también, aunque a veces en otra dirección. Jacinto Carlos Gomes, el abuelo ficcional, desarrolla en su Madeira natal una empresa automotriz que se extiende gradualmente a las Azores, las Canarias y la misma Lisboa. Su nieto venezolano ya no alcanza a pronunciar bien su nombre, "porque una de las primeras travesuras de mi niñez - dice- fue dejar de hablar la lengua de mis padres" (36). Admirador de la tradición viajera portuguesa y travieso en asuntos de sexo, este abuelo acoge con simpatía al nieto venezolano y preadolescente ("Entâo, vieste de barco", le dice, en portugués) y muestra su comprensión cómplice, al dibujarlo ocupado en prácticas propias de la sexualidad manual. Este abuelo Jacinto tiene el mérito de ser el primer representante de una genealogía de progenitores fantasmas de los personajes gomesianos que se desarrollará con fuerza en los relatos por venir.

Nueve años después, luego de concluir su doctorado e iniciarse como profesor, Gomes publica en breve lapso una secuencia de tres volúmenes que forman parte de un mismo y consistente proyecto narrativo y deben ser considerados por la crítica teniendo en cuenta esa interrelación. Son 20 cuentos, algunos reiterados de un volumen a otro, que vienen incluidos en De fantasmas y destierros (2003), Un fantasma portugués (2004) y Viviana y otras historias del cuerpo (2006). ${ }^{7}$ En general y a diferencia de los cuentos mínimos de Visión memorable y de los breves de La cueva de Altamira, encontramos ya aquí algunas piezas bastante extensas en las que se percibe además un talante novelístico por su mayor complejidad y produc-

${ }^{7}$ En adelante, identificaremos estos volúmenes con las iniciales de sus respectivos títulos: De fantasmas y destierros (DFD), Un fantasma portugués (UFP) y Vivianay otras historias del cuerpo (VHC). 
tiva morosidad. De hecho, alguno de ellos, como "Música antigua" o "El vuelo de Sebastián da Silva" puede leerse como nouvelles o novelas cortas. A continuación y ya para concluir, trataremos de explorar algunos rasgos distintivos de este proyecto cuentístico único que coyunturalmente ha sido editado en tres volúmenes, prestando particular atención a su manera de ficcionalizar la "condición migrante".

\section{Los persistentes fantasmas de los migrantes}

Como sugiere la inclusión de la palabra "fantasma" en el título de dos de los tres libros en consideración, en estos cuentos los antepasados portugueses y españoles se quedan con nosotros tras su muerte, repitiendo sus quejas y obsesiones. Estos fantasmas, con frecuencia aceptados de la manera más natural como parte de la familia, parecieran cumplir, como quería de Certeau (1993), la función de impedir el olvido de los aportes particulares que hicieron en vida, de hacer notar que el legado de los ancestros continúa presente en las nuevas generaciones, como se muestra en las líneas iniciales de "Um fantasma português, com certeza", cuento titulado y pleno de citas en lengua portuguesa, elegido como cierre tanto de Un fantasma portugués, como de De fantasmas y destierros:

El fantasma de mi padre se nos apareció por primera vez a las tres horas del entierro. Estaba sentado en el sofá del estudio con un libro abierto en el regazo y la lámpara prendida (no se sabía bien por qué: eran sólo las cinco de la tarde y él, en esas cosas siempre había sido muy ahorrativo) [...] (UFP 98)

A través de la historia de este fantasma gruñón que se niega a hablar en español y de su hijo venezolano, este cuento relativamente breve recoge especialmente bien muchos elementos de la condición migrante. Describe las razones políticas que en los primeros años cincuenta hicieron huir al militante comunista de la policía del dictador Salazar y lo obligaron abordar un barco que "iba cargado 
de españoles e italianos que se dirigían a Venezuela, cuando ésta estaba de moda; aportaba en Funchal y allí se acababa de llenar con nuevos acentos, vino y bacalao." (UFP 99). Al aludir también claramente a la amenazante situación política, social y económica de la actual Venezuela "bolivariana", ofrece las razones por las cuales tanto el fugitivo de entonces como su hijo, profesor universitario, llegan a optar por el regreso a Portugal. En efecto, un tío ya anciano invita desde Funchal a este último a encargarse de su librería. Lo que lo termina de convencerlo de desandar los pasos de su padre es la noticia de que "en estos momentos había en Madeira más personas nacidas en Venezuela que en Venezuela portugueses" (102). El profesor, convertido ya en librero, aparece en realidad como un escritor que al final del cuento nos revela su sentir (o lo que en ese punto de la lectura creemos que es su sentir) de la escritura y de la condición migrante:

Repaso estas páginas y advierto que me expreso como si no me hubiera movido de Caracas. Creo que en cualquier rincón del mundo anotaría mis pensamientos y divagaciones de la misma manera. Pero no me engaño: esa ciudad nunca me perteneció; tampoco me pertenecen otras. Acaso por eso todavía escribo, y en un idioma ajeno. (UFP 103)

Con esas palabras, se asume, se construye, como una "figura de afuera", según la concepción aludida por Aínsa. En realidad, el migrante lleva los diversos mundos viajados y vividos dentro de sí y su postura o perspectiva no depende tanto de la ubicación geográfica o cultural del momento presente como de esas vivencias que son ya parte constitutiva de su ser. Como prueba fehaciente de esta multiculturalidad interior, unas líneas más adelante, el lector de este cuento intenso y entrañable es sorprendido por la revelación de quién es, más allá de la muerte, el verdadero autor de las páginas que así concluyen y que -lúdicamente- constituyen el texto mismo del cuento.

En el relato que lleva su nombre, la abuela Mineta (DFD y VHC) es otro de esos fantasmas. Para cuatro generaciones de portugueses 
migrantes e hijos de migrantes, sus cantos y sus silbidos han constituido un símbolo muy claro de la permanencia de la tradición: "A la abuela la mató una mala diabetes. [...] Pero la bruja Margarida no murió del todo, porque le cantó a su hijo la historia de Mineta, él me la cantó a mí y yo se la he repetido a Michael" (18). Tras su muerte, que el cuento representa en detalle, también el padre del narrador anónimo adquiere, como hemos visto, hábitos fantasmales. Cargado de simbolismo viene el rito de despedida, donde el narrador y su hijo arrojan al mar, frente a la ciudad de New Haven, Connecticut: "una caña de pescar, la caja de puros y los tres pasaportes del abuelo" (DFD 21).

Hasta en relatos enfocados en otras preocupaciones de carácter más general, como "El desierto" (DFD), se menciona como de paso la condición migrante del protagonista, cuyo extremo sentimiento de mediocridad, rutina, hastío y soledad, una vez dejado atrás todo interés por el sexo, el trabajo y la jardinería, incluye un matiz que describe como "detenerse a sentir nostalgia, un número constante de ocasiones al año [...] por el país remoto donde naciste y al que nadie sabe si algún día te tocará volver.” (DFD 40). El tema del padre fallecido pero muy presente se repite en el relato "Música antigua", cuyo solitario protagonista casi no llegó a conocerlo, pero se relaciona con él a través de la mutua afición por la música.

En el liviano "Cuento gótico", hay una fantasma portuguesa que se aparece (desempeñando su papel más en serio, aunque con no poco humor) a tres vecinas de Nueva Inglaterra apellidadas Sullivan (norteamericana aparentemente, aunque llamada Dolores), Alario (italiana) y Varella (portuguesa). Ellas logran adivinar que lo que la insistente fantasma quiere saber es el paradero de su filho, quien solía habitar en la casa de Mrs. Sullivan. Lo entretenido del relato es que se trata de un inusual fantasma femenino, que que la señora aun después de muerta tiene problemas de oído, que requiere traducción simultánea y que al final es remitida (pero erróneamente) a otra casa del mismo pueblo donde supuestamente se ha mudado el hijo tan buscado.

Como puede apreciarse en lo que ya llevamos andado, en la mayoría de las piezas de ambos libros, el fantasma de los padres o 
de los abuelos sigue presente en el seno de estas familias acostumbradas a sucesivos viajes, asentamientos y adaptaciones forzados por la necesidad, a través de personajes ficcionales coherentes y convincentes que logran ingresar en el patrimonio simbólico del lector. La sostenida indagación de esta temática de los migrantes a través de historias muy diversas viene a constituir además un robusto y eficiente desmentido a los abusivos y planos lugares comunes atribuidos (al menos en Venezuela) a los inmigrantes portugueses, imaginándolos como verduleros crudos y peseteros (de Abreu 132-136). En su lugar, los personajes de la narrativa de Gomes son atractivos por lo complejos, ilustrados, sensibles y orgullosos con razón de su pasado. En efecto, como en una suerte de revancha poética a larga distancia, abundan en estas historias los lusitanos insulares y continentales (y también los vascos, catalanes, gallegos, canarios, navarros, aragoneses, etc.) que son, investigadores, editores, libreros, lectores exquisitos, conocedores de música o artes plásticas, aunque se ganen la vida como vendedores de seguros; pero, por encima de todo, profesores universitarios.

\section{Otras claves del universo gomesiano}

Si nos proponemos resumir en esta sección final otros rasgos relevantes de la cuentística gomesiana, además de los ya mencionados en relación con la dominante temática de la condición migrante, éste último aspecto sería tal vez uno de los más visibles: los profesores, casi siempre migrantes ellos mismos, están presentes con suma frecuencia entre los personajes protagónicos y secundarios. La pieza que destaca de manera especial en esta línea es, sin duda "El vuelo de Sebastián da Silva" (UFP), uno de los más extensos, donde se radiografía de la manera más cruda la azorada vida de los profesores de literaturas hispánicas e hispanoamericanas en los Estados Unidos, con particular atención a la frecuente confrontación (que en ocasiones tiene lugar en el interior de la misma persona o personaje) del escritor y el catedrático, del impulso artístico del narrador 
de ficciones y el impulso cognoscitivo y sistematizador del investigador y docente de la literatura.

Otra llamativa recurrencia como tema y circunstancia narrativa tienen los personajes masculinos, no pocas veces de edad madura, que por diversas razones se encuentran en situación de soledad física y a la vez emocional. Uno de los momentos cumbres de esta aproximación narrativa a la soledad es la nouvelle "Música antigua", donde un burócrata solitario nos asombra con su erudición musical. A través de ese personaje hijo de un profesor catalán y de una caraqueña licenciada en Letras, Gomes realiza una minuciosa y avasalladora exploración de la soledad de un erudito en una adusta ciudad del Midwest norteamericano. Mediante trabajados monólogos interiores, este solitario nos comunica su descubrimiento, a distancia y sólo a través de un duelo de exquisitez musical con uno de sus esquivos vecinos, de que él no es en aquel medio "el único raro, el único weirdo que albergaba sensibilidades superiores a las de las faenas rurales..." (DFD 57).

Un indicio más definitivo aún de la integridad y vertebración del proyecto narrativo gomesiano es la vinculación que el lector más desprevenido va advirtiendo de no pocos de los relatos con una empresa o institución específica, con su contexto laboral, con el personal que en ella se desempeña y con las respectivas relaciones de algunos de los miembros de ese staff. Se establece así en buena parte del conjunto una suerte de red o rizoma narrativo de extraordinaria eficiencia que capitaliza las virtudes del cuento y la novela, como puede apreciarse al leer consecutivamente, por ejemplo, "Arte y sexualidad en el mundo occidental" (VHC) y "Los efectos de Mateo Flecha sobre la carne" (UFP).

Gomes tiene también un marcado interés por el cuerpo y sus exigencias, en especial las relacionadas con el sexo. En el volumen titulado justamente Viviana y otras historias del cuerpo, prácticamente todos los relatos realizan aproximaciones llamativamente originales al organismo físico. La sexualidad está presente en la mayoría de las piezas narrativasy con frecuencia se dedican a explorar sus facetas menos conocidas o codificadas, como el erotismo con barriga de embarazo y doble triángulo amoroso en "Lamaze (folletín lascivo 
con catalanes)"; o el exhibicionismo-voyeurismo en el cuento "Jesús", donde la excitación de quien a diario se muestra desnudo al bañarse se funda en su imaginación (engañosa y finalmente ambigua, por cierto) de quién lo contempla desde una ventana indiscreta. Cuerpos narrados, en fin, con un fino humor, fundado en la implicación y la sugerencia y sostenido por una deliciosa complicidad con el lector.

Otro apunte caracterizador tendría finalmente que destacar la relevancia del lenguaje oral y escrito. Si todos los elementos de la cultura tienen su participación en las dificultades de adaptación del trashumante, la palabra hablada y escrita son, en no pocas de estas historias, el espacio paradójico y reverberante donde se producen a la vez las más violentas fricciones de lo diferente y los más fértiles encuentros e intercambios, como se evidencia magníficamente en piezas como "Los efectos de Mateo Flecha sobre la carne" (UFP), "El silencio de la noche" (VHC) o "El poeta fantasma" (VHC).

Hemos encontrado en la narrativa de Miguel Gomes una consistente y multiforme atención a la condición migrante a través de variaciones en el triángulo Portugal/Venezuela/Costa Este de los Estados Unidos; la múltiple cercanía de los fantasmas familiares afanados en recordarnos de no olvidar; la exploración ficcional de temas predilectos suyos como la soledad masculina, la vida académica norteamericana, o las facetas inéditas del cuerpo o el lenguaje; y nos hemos asomado a la consistencia estructural de un proyecto cuentístico reforzada por la planificada imbricación de ambientes, personajes y situaciones. Sobre el universo ficcional de Miguel Gomes y sobre otros narradores que se interesan por la trashumancia en el contexto prometedor de la nueva narrativa venezolana habrá que seguir indagando, pero es hora ya de concluir.

Releo todo lo anterior y me pregunto, con un dejo casi confesional, por qué me habrá interesado, justo en este momento de mi carrera y de mi vida, indagar sobre la representación ficcional de las multipolares migrancias de mi país. Antes venían a Venezuela de muchas partes como a una tierra prometida. Ahora tantos venezolanos se han ido o consideran con angustia la posibilidad de dejar ese país suyo, donde la intransigencia y el autoritarismo popu- 
lista mal disfrazados de revolución de izquierda han cerrado y siguen cerrando tantas puertas. ¿Será porque estoy comenzando a convertirme en un migrante, sin haber cambiado de lugar, por el hecho de estar siendo tratado en mi propio país como un extraño, como un extranjero, como un enemigo, excluido y públicamente recriminado, por no compartir las posiciones oficiales y manifestarlo abiertamente? ¿Será porque, antes aún de considerar siquiera la desgarradora posibilidad de tener que abandonar la tierra de mis padres y abuelos que quiero siga siendo la de mis hijos y nietos, ya estoy viviendo y por tanto comprendiendo mejor lo que es la condición migrante?

Caracas, agosto de 2007 -Cincinnati febrero de 2008.

\section{Bibliografía}

Adorno, Theodor. Minima Moralia. Torino: Einaudi, 1971.

Aínsa, Fernando. "La patria literaria, más allá de la periferia." Conferencia dictada en la Escuela de Letras de la Universidad Central de Venezuela el UCV el 17 de octubre de 2007. Texto en proceso de publicación en la revista Akademos (Dirección de Postgrado de la Facultad de Humanidades y Educación de la UCV).

Ascencio, Michaelle. El viaje a la inversa. (Reflexiones acerca del exilio en la narrativa antillana). Caracas: Fondo Editorial de Humanidades y Educación, 2004. Universidad Central de Venezuela.

Barrera Linares, Luis. "Nuevos aires para la narrativa venezolana." La duda melódica. <http://barreralinares.blogspot.com/2006/ 11 / nuevos-aires-para-la-narrativa.html>.

Berglund, Susana. "La población extranjera en Venezuela de Castro a Chávez." VVAA: Las inmigraciones a Venezuela en el siglo XX. Caracas: Fundación Francisco Herrera Luque/Banco Mercantil, 2005.

Boadas, Aura Marina. "Exilio y desarraigo en la narrativa de Renato Rodríguez." XXII Simposio Anual de la Asociación Venezolana de Estudios del Caribe (AVECA): "Caribe endógeno/Caribe exógeno". Cumaná, 20 al 22 de noviembre de 2006. En proceso de publi- 
cación en la revista Núcleo, Escuela de Idiomas Modernos de la UCV. Ponencia.

Bujanda, Héctor. La última vez. Caracas: Editorial Norma, 2006 Premio de Novela “Adriano González León”..

Chambers, Iain. Migración, cultura, identidad. Buenos Aires, Amorrortu Editores, 1994.

Cornejo Polar, Antonio. "Condición migrante e intertextualidad multicultural: el caso de Arguedas." Revista de Crítica Literaria Latinoamericana 42 (1994): 101-109. (Lima-Berkeley).

De Abreu Xavier, Antonio. Con Portugal en la maleta. Historias de vida de los portugueses en Venezuela. Siglo XX. Caracas. Editorial Alfa, 2007.

De Certeau, Michel. La escritura de la historia. México: Editorial Iberoamerica, 1993. Primera edición en francés: L’Écriture de l'histoire 1978.

De Stefano Victoria (2007): “La refiguración del viaje: Mi padre el inmigrante de Vicente Gerbasi (1913-1992).” Hofstra Hispanic Review 5 (2007): 28-43.

García Canclini, Néstor. Consumidores y ciudadanos. Conflictos multiculturales de la globalización. México: Grijalbo, 1995.

. Cultura y comunicación: entre lo global y lo local. La Plata: Universidad Nacional de La Plata, 1997. Facultad de Periodismo y Comunicación Social.

Gomes, Miguel. Visión memorable. Caracas: Fundarte, 1987.

—. La cueva de Altamira. Caracas: Alfadil, 1992.

sidad EAFIT, 2003.

—. Un fantasma portugués. Caracas: Otero Ediciones, 2004.

- Viviana y otras historias del cuerpo. Caracas: Random House Mondadori, 2006.

Grinberg, León y Rebecca. Psicoanálisis de la migración y del exilio. Madrid: Alianza, 1984.

Grinberg, León. Migración y exilio. Estudio psicoanalitico. Madrid: Editorial Biblioteca Nueva, 1996.

López Ortega, Antonio. "Editorial” Veintiuno 2 diciembre 2004enero 2005: 2 
Núñez, Marielba. "Se fuga la inteligencia." El Nacional (Caracas) 27de enero de 2008: A1, S1, S2 y S3. Versión digital disponible a través del enlace: $<$ http://impresodigital.el-nacional.com/ediciones $/ 2008 / 01 / 27$ default.asp?cfg=3512BLLH3097\&iu=6713>

Pacheco, Carlos. "Miguel Gomes en la cresta del tsunami narrativo." Imagen Latinoamericana. 1 (2005): 37-42.

. "Las fibras tiernas." Papel Literario de El Nacional. 3 de marzo de 2007: 8-9.

Rivas, Luz Marina. La literatura de la otredad: cuentistas venezolanas 1940-1956. Tesis de Maestría en Literatura USB, 1992. Premio APUCV al mejor trabajo de ascenso 1992. Inédita.

. Las mujeres toman la palabra. Caracas: Monte Ávila Editores. 2004.

. "El país dentro de la casa y la casa que se derrumba: la nueva narrativa femenina." VI Jornadas de Investigación Lingüística y Literaria de la Universidad del Zulia, Maracaibo, 25 al 28 de septiembre de 2007. Conferencia.

Rodríguez Ortiz, Oscar. "Los que vinieron a inventar." Las migraciones a Venequela en el siglo XX. Caracas: Fundación Herrera Luque /Banco Mercantil, 2005. 189-195.

Said, W. Edward. "Recuerdo del invierno." Punto de Vista. 22 (1984): 3-7.

Saraceni, Gina. Escribir la intemperie. Desarraigo, pérdida y extravio en tres autores de la memoria (1990-1998). Proyecto de tesis doctoral. Universidad Simón Bolívar, 2000.

Stavans, Ilan. La condición hispánica. Reflexiones sobre cultura e identidad en los Estados Unidos. México: Fondo de Cultura Económica, 1999.

Todorov, Tzvetan. El hombre desplazado, Madrid: Taurus, 1998.

Zambrano, Gregory. "Condición migrante e hibridación cultural: algunos casos en la literatura venezolana." VII Jornadas Andinas de Literatura Latinoamericana, JALLA 2006. Bogotá, 14 al 18 de agosto de 2006. Publicación digital. 